\title{
Lubrication of Rough Short Bearing on Shliomis Model by Ferrofluid Considering Viscosity Variation Effect
}

\author{
Mohmmadraiyan M. Munshi \\ Alpha College of Engineering and Technology \\ Gujarat Technological University, Kalol, 382721, Gujarat, India \\ Corresponding author: raiyan.munshi@gmail.com \\ A. R. Patel \\ Vishwakarma Government Engineering College \\ Gujarat Technological University, Ahmedabad, 382424, Gujarat, India \\ E-mail: dr.arpate169@gmail.com \\ G. M. Deheri \\ Department of Mathematics \\ Sardar Patel University, Vallabh Vidhyanagar, 388120, Gujarat, India \\ E-mail: gm.deheri@ rediffmail.com \\ (Received January 16, 2019; Accepted May 1, 2019)
}

\begin{abstract}
This study aims to explore the impact caused by change in viscosity and the roughness of a bearing surface on a ferrofluid lubrication of Shliomis model for short bearing. Based on this model and the Tipei (1962) model, a new resultant Reynolds equation has been found that shows thermal variation. The Christensen and Tonder models have been taken to derive the transverse roughness stochastically. An assumed mean has been taken for the probability density function with a non-zero value. This value is assigned to a random variable that measures the bearing's surface roughness. This creates a more realistic situation that can have a lot of field applications. The model defines the problem mathematically while defining boundary conditions. It also uses the Simpson's method to derive a conclusion. The results thus obtained are discussed in terms of pressure distribution and load bearing capacity. The graphical results obtained suggest that in the presence of magnetization, there is a significant enhance in the load bearing capacity. This positive effect can easily nullify the negative impact of the thermal effect. The short bearing approximation shown here is an example of the probable applications. Ferrofluids in the presence of magnetic fields significantly enhance the performance of a short bearing.
\end{abstract}

Keywords- Ferrofluid, Thermal variation, Load carrying capacity.

\section{Introduction}

Analytical studies performed on hydrodynamic lubrication in a short-bearing non-porous system are very popular. Many famous books of the field (Hamrock, 1994; Bhat, 2003; Majumdar, 2008) discuss the Reynolds equation and try to derive an exact solution to it by using different basic film geometries.

All the particles undergo a body force when subjected to a magnetic field, resulting in the drag to flow. Therefore, for industrial application, the study of lubrication with magnetic fluid is of primary importance. Some researchers (Deheri et al., 2016; Munshi et al., 2017; Patel et al., 2017; Vashi et al., 2018) have also used magnetic fluid as a lubricant in order to aid the tribological performance of a sliding interface. 
International Journal of Mathematical, Engineering and Management Sciences

Vol. 4, No. 4, 982-997, 2019

https://dx.doi.org/10.33889/IJMEMS.2019.4.4-078

Christensen and Tonder (1969a, b; 1971) used a stochastic concept and came up with a new model for lubricated surfaces with striated roughness using an averaging film. They derived the stochastic Reynolds' equation and used the results to study the impact of surface roughness on the load bearing capacity in a rough bearing system. Shliomis (1974) analyzed the modes of creating magnetic colloids along with the stability concerns. Patel et al. (2010a) studied the efficiency and effectiveness of a short bearing with a smooth surface. Deheri and Patel (2011) and Patel et al. (2010b) studied the effectiveness of a short bearing with roughness having a mean zero. They worked with a variety of magnetic field magnitudes for their study. Shimpi and Deheri (2010) further worked on the results of (Deheri and Patel, 2011; Patel et al., 2010b) focusing on short bearings with non-zero mean with different form of magnetic field magnitude. Shimpi and Deheri (2012) worked on it by including a deformation effect as well. Patel and Deheri (2013a) further studied comparing two different types of porous structures. Patel and Deheri (2013b) extended the study of (Patel et al., 2010a) by adding the aspect of slip velocity. They concluded that optimal performance can only be achieved at minimum slip. It should be noted that the researches mentioned above used the Neuringer-Rosensweig model. Patel et al. (2015) conducted a different study by replacing the hydrodynamic bearing of the above-mentioned studies with hydromagnetic porous short bearing. Additionally, it is a commonly known fact that roughness impacts the load bearing capacity substantially.

Transformation of heat problem has been investigated with non-Newtonian fluid by (Singh et al., 2018). The positive and negative wall inclination design chart, demonstrate through (Gupta et al., 2019). Ramadevi et al. (2018) introduced a new arena in the respective field where the viscosity of fluid and partial slip velocity involved. The payload capacity of amphibious vehicle with $7 \mathrm{~kg}$ conceptual designed by (Gokul Raj et al., 2019). Khamari et al. (2019) represented the impact toughness and microstructure comparison.

A lot of research in the field of Tribology today also focuses on the impact caused by hydrodynamic lubrication. Most of the studies take viscosity to be a constant value even though it is a function of temperature as well as pressure. The change in viscosity caused due to temperature is very crucial in a majority of the practical applications where the lubricants are expected to perform under different values of temperature (Freeman, 1962). Tipei (1962) performed an experimental study which suggested that the viscosity-temperature relationship is substitutable by a establishing a relationship between the viscosity and the film thickness. The study also suggested that least film thickness is associated with highest temperature. The study by Sinha et al. (1981) focused on lubrication of an extremely small and an infinitely long short journal bearing. The results proved that changes in viscosity reduce the load and friction coefficient. In this modern age, various research and articles is in existence which can help a researchers as well as in the field of research for different kind of bearing using Shliomis model such as, (Lin et al., 2013a) in long journal bearing, (Lin et al., 2013b) in short journal bearing considering non-newtonian fluid, (Huang and Wang, 2016) in short bearing while using different forms of viscosity, (Lin, 2016) in short journal bearing considering longitudinal roughness and various forms of viscosity. The impact of thermal effect on Journal bearing is studied by a lot of researchers using a number of different parameters. For example, (Reddy et al., 2012) used couple stress fluid, (Kumar et al., 2013) studied the model using two layer fluid considering cavitation, (Siddangouda et al., 2013) studied roughness, (Naduvinamani et al., 2014) used Micropolar fluid and different forms of transverse and longitudinal roughness, (Patel et al., 2018) used Neuringer-Rosensweig model taking into account smooth roughness. 
International Journal of Mathematical, Engineering and Management Sciences

Vol. 4, No. 4, 982-997, 2019

https://dx.doi.org/10.33889/IJMEMS.2019.4.4-078

By reviewing literature concerning ferrofluid flow, one can understand that Shliomis model displays better results than Neuringer-Rosensweig model. Thus, this study is focused on scrutinizing the performance of thermal effect on ferrofluid lubrication using short bearing based on Shliomis model.

\section{Analysis}

The Figure 1 shows the geometrical design of the system and its configurations. $U$ denotes the uniform velocity of the system in the direction $x$.

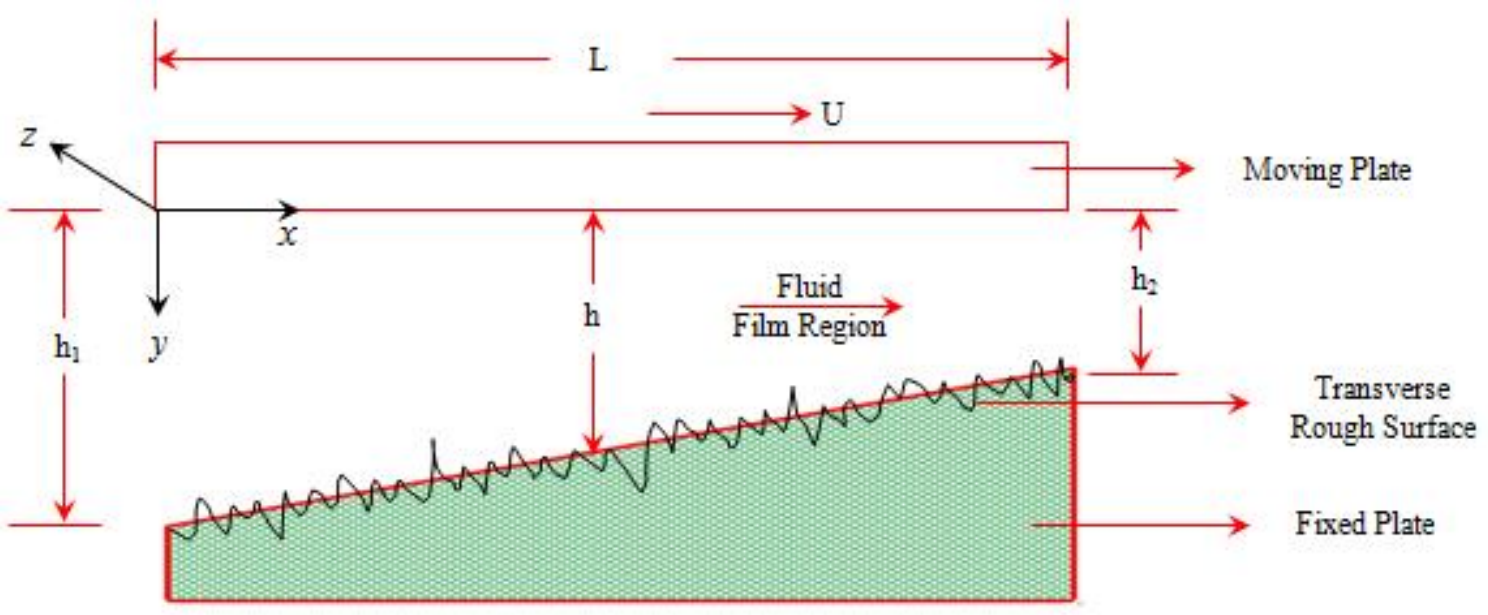

Figure 1. Configuration of the bearing system (Patel and Deheri, 2013a)

The thickness $\boldsymbol{h}$ is,

$\boldsymbol{h}=h+h_{s}$

where $h$ is taken as (Patel and Deheri, 2013a):

$$
h=h_{2}\left[1+m\left(1-\frac{x}{L}\right)\right], m=\frac{h_{1}-h_{2}}{h_{2}}
$$

using the works of (Christensen and Tonder, $1969 \mathrm{a}, \mathrm{b}$; 1971). Also, the study uses $h_{s}$ using the probability density function

$f\left(h_{s}\right)= \begin{cases}\frac{35}{32 c}\left(1-\frac{h_{s}^{2}}{c^{2}}\right)^{3}, & -c \leq h_{s} \leq c \\ 0 & , \text { elsewhere }\end{cases}$ 
International Journal of Mathematical, Engineering and Management Sciences

Vol. 4, No. 4, 982-997, 2019

https://dx.doi.org/10.33889/IJMEMS.2019.4.4-078

In this case, $c$ is the highest possible deviation from the average width of the film. $\alpha, \sigma$ and $\varepsilon$ are considered in view of relationship

$\alpha=E\left(h_{s}\right), \sigma^{2}=E\left(h_{s}-\alpha\right)^{2}, \varepsilon=E\left(h_{s}-\alpha\right)^{3}$

where $E(\bullet)$ denotes the expectancy operator known by

$E(\bullet)=\int_{-c}^{c}(\bullet) f\left(h_{s}\right) d h_{s}$

Actually, magnetic fluids or the ferrofluids have a constant nature and are the type of colloidal suspensions that possess extremely superior magnetic particles in a viscous fluid. We can use an external magnetic field to position, limit or monitor these fluids as required. This, in turn, increases the fluid's effective viscosity. This research has substantially contributed to the increase application of these magnetic fluids in bearing systems as lubricating agents. An important point here is that most of the studies based on Neuringer-Rosensweig model have concluded that the vector of magnetization is parallel to the applied magnetic field. Since Shliomis model considers particle rotation, it overcomes this limitation.

Shliomis (1974) proposed that a change in applied magnetic field can have a two-way implication on the particles in a magnetic fluid. Either, the rotation of such particles is impacted or the magnetic moment in them changes. $\tau_{B}$ (Brownian relaxation time parameter) is used to derive the particle rotation and $\tau_{S}$ (relaxation time parameter) suggests the intrinsic process of rotation. Considering a steady flow while overlooking the second derivatives and inertial of $\bar{S}$, the revised flow equation becomes,

$-\nabla p+\eta \nabla^{2} \bar{q}+\mu_{0}(\bar{M} \cdot \nabla) \bar{H}+\frac{1}{2 \tau_{s}} \nabla \times(\bar{S}-I \bar{\Omega})=0$

$\bar{\Omega}=\frac{1}{2} \nabla \times \bar{q}$

$\bar{S}=I \bar{\Omega}+\mu_{0} \tau_{s}(\bar{M} \times \bar{H})$

$\bar{M}=M_{0} \frac{\bar{H}}{H}+\frac{\tau_{B}}{I}(\bar{S} \times \bar{M})$

$\nabla \times \bar{H}=0$

and

$\nabla(\bar{H}+\bar{M})=0$

The following can be derived by combining all the mentioned equations

$-\nabla p+\eta \nabla^{2} \bar{q}+\mu_{0}(\bar{M} \cdot \nabla) \bar{H}+\frac{1}{2} \mu_{0} \nabla \times(\bar{M} \times \bar{H})=0$ 
International Journal of Mathematical, Engineering and Management Sciences

Vol. 4, No. 4, 982-997, 2019

https://dx.doi.org/10.33889/IJMEMS.2019.4.4-078

$\bar{M}=M_{0} \frac{\bar{H}}{H}+\tau_{B} \bar{\Omega} \times \bar{M}+\frac{\mu_{0} \tau_{B} \tau_{s}}{I}(\bar{M} \times \bar{H}) \times \bar{M}$

Langevin's parameter $\xi>1$ is used for the strong magnetic field, the above equation changes to

$\bar{M}=\frac{M_{0}}{H}\left[\bar{H}+\tau_{B}(\bar{\Omega} \times \bar{H})\right]$

with

$\bar{\tau}=\frac{6 \eta \phi}{n k_{B} T(1+\xi \operatorname{coth} \xi)}$

where

$M_{0}=n \mu\left(\operatorname{coth} \xi-\frac{1}{\xi}\right), H=\frac{k_{B} T \xi}{\mu_{0} \mu}$

For a deferment of spherical particles:

$\frac{I}{\tau_{s}}=6 \eta \phi$ and $\tau_{B}=\frac{3 \eta V}{k_{B} T}$

With uniform magnetic field $\bar{H}=\left(0, H_{0}, 0\right)$, (11) to (13) develop into the following (Majumdar, 2008)

$\frac{\partial p}{\partial x}=\frac{\partial}{\partial y}\left(\eta(1+\tau) \frac{\partial u}{\partial y}\right)$

$\frac{\partial p}{\partial y}=0$

$\frac{\partial p}{\partial z}=\frac{\partial}{\partial y}\left(\eta(1+\tau) \frac{\partial w}{\partial y}\right)$

and

$\frac{\partial \rho}{\partial t}+\frac{\partial}{\partial x}(\rho u)+\frac{\partial}{\partial y}(\rho v)+\frac{\partial}{\partial z}(\rho w)=0$

where (referring to Shliomis, 1974)

$\tau(\phi, \xi)=\frac{3}{2} \phi \frac{\xi-\tanh \xi}{\xi+\tanh \xi}$

and 
International Journal of Mathematical, Engineering and Management Sciences

Vol. 4, No. 4, 982-997, 2019

https://dx.doi.org/10.33889/IJMEMS.2019.4.4-078

$\eta=\eta_{0}\left(\frac{h}{h_{2}}\right)^{q}$

The above equation denotes thermal variation considering the viscosity-temperature, when the viscosity $\eta_{0}$ at $h=h_{0}$, whereas $q$, the thermal factor, usually maintain the value between 0 and 1 according to the nature of the lubrication (Tipei, 1962).

Solving equation (17) under no slip boundary conditions (Majumdar, 2008);

at $y=0, u=u_{b}, w=w_{b}$ and

at $y=\boldsymbol{h}, u=u_{a}, w=w_{a}$

One can find

$$
\begin{aligned}
& u=\frac{1}{2 \eta(1+\tau)} \frac{\partial p}{\partial x} y(y-\boldsymbol{h})+\left(\frac{\boldsymbol{h}-y}{\boldsymbol{h}}\right) u_{b}+\frac{y}{\boldsymbol{h}} u_{a} \\
& w=\frac{1}{2 \eta(1+\tau)} \frac{\partial p}{\partial z} y(y-\boldsymbol{h})+\left(\frac{\boldsymbol{h}-y}{\boldsymbol{h}}\right) w_{b}+\frac{y}{\boldsymbol{h}} w_{a}
\end{aligned}
$$

Putting the velocity components expression into continuity equation (18) and integrating under the conditions $v=v_{b}$ at $y=0$ and $v=v_{a}$ at $y=\boldsymbol{h}$ gives rise to;

$$
\begin{aligned}
\rho\left(v_{a}-v_{b}\right)= & -\frac{1}{2}\left\{\int_{0}^{h} \frac{\partial}{\partial x}\left[\frac{\rho}{\eta(1+\tau)} \frac{\partial p}{\partial x} y(y-\boldsymbol{h})\right] d y+\int_{0}^{h} \frac{\partial}{\partial z}\left[\frac{\rho}{\eta(1+\tau)} \frac{\partial p}{\partial z} y(y-\boldsymbol{h})\right] d y\right\} \\
& -\int_{0}^{h} \frac{\partial}{\partial x}\left[\rho\left\{\left(\frac{\boldsymbol{h}-y}{\boldsymbol{h}}\right) u_{b}+\frac{y}{\boldsymbol{h}} u_{a}\right\}\right] d y-\int_{0}^{h} \frac{\partial}{\partial z}\left[\rho\left\{\left(\frac{\boldsymbol{h}-y}{\boldsymbol{h}}\right) w_{b}+\frac{y}{\boldsymbol{h}} w_{a}\right\}\right] d y \\
& -\boldsymbol{h} \frac{\partial \rho}{\partial t}
\end{aligned}
$$

In reference to experiment through the utilization of relation (Majumdar, 2008)

$$
\int_{0}^{\boldsymbol{h}} \frac{\partial}{\partial x}[f(x, y, z)] d z=\frac{\partial}{\partial x} \int_{0}^{\boldsymbol{h}} f(x, y, z) d z-f(x, y, \boldsymbol{h}) \frac{\partial \boldsymbol{h}}{\partial x}
$$

One obtains for constant velocities

$$
\frac{\partial}{\partial x}\left(\frac{\rho \boldsymbol{h}^{3}}{12 \eta(1+\tau)} \frac{\partial p}{\partial x}\right)+\frac{\partial}{\partial z}\left(\frac{\rho \boldsymbol{h}^{3}}{12 \eta(1+\tau)} \frac{\partial p}{\partial z}\right)=\frac{U}{2} \frac{\partial}{\partial x}(\rho \boldsymbol{h})+\frac{\partial}{\partial t}(\rho \boldsymbol{h})
$$

where

$$
U=u_{a}+u_{b}
$$


International Journal of Mathematical, Engineering and Management Sciences

Vol. 4, No. 4, 982-997, 2019

https://dx.doi.org/10.33889/IJMEMS.2019.4.4-078

The generalized Reynolds' equation (24) turns in the state of equilibrium, which brings (Majumdar, 2008)

$\frac{\partial}{\partial x}\left(\frac{\rho \boldsymbol{h}^{3}}{12 \eta(1+\tau)} \frac{\partial p}{\partial x}\right)+\frac{\partial}{\partial z}\left(\frac{\rho \boldsymbol{h}^{3}}{12 \eta(1+\tau)} \frac{\partial p}{\partial z}\right)=\frac{U}{2} \frac{\partial}{\partial x}(\rho \boldsymbol{h})$

Modified two dimensional Reynolds' equation, for the incompressible lubricant is

$$
\frac{\partial}{\partial x}\left(\frac{\boldsymbol{h}^{3}}{12 \eta(1+\tau)} \frac{\partial p}{\partial x}\right)+\frac{\partial}{\partial z}\left(\frac{\boldsymbol{h}^{3}}{12 \eta(1+\tau)} \frac{\partial p}{\partial z}\right)=\frac{U}{2} \frac{\partial \boldsymbol{h}}{\partial x}
$$

In the $x$-direction, the flow because of pressure gradient in the variation of pressure can be avoided when the bearing is short. In this case, the one dimensional equation (27) lead to:

$$
\frac{\partial}{\partial z}\left(\boldsymbol{h}^{3} \frac{\partial p}{\partial z}\right)=6 \eta(1+\tau) U \frac{\partial \boldsymbol{h}}{\partial x}
$$

which is the Reynolds' equation (Basu et al., 2005; Majumdar, 2008; Shimpi and Deheri, 2010) modified according to the general hydrodynamic lubrication assumptions.

According to the stochastically average process of (Shimpi and Deheri, 2010), (28) becomes:

$$
\begin{aligned}
& \frac{\partial}{\partial z}\left(E\left(\boldsymbol{h}^{3}\right) \frac{\partial p}{\partial z}\right)=6 \eta(1+\tau) U \frac{\partial}{\partial x}(E(\boldsymbol{h})) \\
& \frac{\partial}{\partial z}\left(g(h, \alpha, \sigma, \varepsilon) \frac{\partial p}{\partial z}\right)=6 \eta(1+\tau) U \frac{\partial}{\partial x}(h+\alpha)
\end{aligned}
$$

where

$$
g(h, \alpha, \sigma, \varepsilon)=h^{3}+3 \alpha h^{2}+3\left(\sigma^{2}+\alpha^{2}\right) h+3 \sigma^{2} \alpha+\alpha^{3}+\varepsilon
$$

The ensuing dimensionless quantities are used,

$$
\begin{aligned}
& X=\frac{x}{L}, Z=\frac{z}{B}, \bar{h}=\frac{h}{h_{2}}=[1+m(1-X)], g(\bar{h}, \bar{\alpha}, \bar{\sigma}, \bar{\varepsilon})=\frac{g(h, \alpha, \sigma, \varepsilon)}{h_{2}{ }^{3}} \\
& \bar{\alpha}=\frac{\alpha}{h_{2}}, \bar{\sigma}=\frac{\sigma}{h_{2}}, \bar{\varepsilon}=\frac{\varepsilon}{h_{2}{ }^{3}}, \bar{p}=\frac{p h_{2}^{3}}{\eta_{0} U B^{2}}, \bar{L}=\frac{L}{h_{2}}, \bar{B}=\frac{B}{h_{2}}
\end{aligned}
$$

The related pressure limit settings are (Deheri and Patel, 2011)

$$
\bar{p}=0 \text { at } Z= \pm \frac{1}{2} \text { and } \frac{\mathrm{d} \bar{p}}{\mathrm{~d} Z}=0 \text { at } Z=0
$$


International Journal of Mathematical, Engineering and Management Sciences

Vol. 4, No. 4, 982-997, 2019

https://dx.doi.org/10.33889/IJMEMS.2019.4.4-078

With the aid of (32) the pressure distribution in dimensionless form overcome with

$\bar{p}=\frac{3 m[1+m(1-X)]^{q}(1+\tau)}{\bar{L} g(\bar{h}, \bar{\alpha}, \bar{\sigma}, \bar{\varepsilon})}\left(\frac{1}{4}-Z^{2}\right)$

where

$g(\bar{h}, \bar{\alpha}, \bar{\sigma}, \bar{\varepsilon})=\bar{h}^{3}+3 \bar{\alpha}^{2}+3\left(\bar{\sigma}^{2}+\bar{\alpha}^{2}\right) \bar{h}+3 \bar{\sigma}^{2} \bar{\alpha}+\bar{\alpha}^{3}+\bar{\varepsilon}$

The bearing ability of dimensionless type (Patel and Deheri, 2013a) is obtained

$\bar{W}=\frac{h_{2}{ }^{3} W}{\eta_{0} U B^{4}}$
$\bar{W}=\frac{m(1+\tau)}{2 \bar{B}} \int_{0}^{1} \frac{[1+m(1-X)]^{q}}{g(\bar{h}, \bar{\alpha}, \bar{\sigma}, \bar{\varepsilon})} \mathrm{d} X$

where the load bearing capacity is calculated using

$W=\int_{-\frac{B}{2}}^{\frac{B}{2}} \int_{0}^{L} p(x, z) \mathrm{d} x \mathrm{~d} z$

\section{Results and Discussion}

Equation (33) shows that the pattern of pressure distribution when in a dimensionless form. Additionally, the bearing system's capacity can be derived using Eq. (36) in a non-dimensional form. When $\bar{\sigma}$, the parameter of roughness is assumed to be 0 , this investigation diminishes to the study of a Ferrofluid based short bearing. If the magnetization constant is also considered 0 , the study becomes a performance analysis of the system as suggested by (Basu et al., 2005). 1/3 rule as given by Simpson having a step size of 0.2 is helpful in calculating the Eq. (36) for altering the measure of magnetization parameter $\tau$, thermal factor $Q$, aspect ratio $m$, roughness parameters $\bar{\alpha}, \bar{\sigma}, \bar{\varepsilon}$.

The final values of $\bar{W}$ using different parameters are plotted graphically. The Figures 2(a-f) display the changes in $\bar{W}$ corresponding to different values of $\tau$. They suggest that magnetization leads to a substantial increase in $\bar{W}$. It is noticed as of Figure 2(c) that the amount of minimum $\bar{W}$ derived is 0.0183 at higher value of $\bar{\sigma}$ with regards to $\tau$. From Figures 3(a-e) it can be suggested that with an increase in $\bar{W}, Q$ shifts from 0 to 1 . Figures 4(a-d) display the impact of aspect ratio on $\bar{W}$ and suggests that aspect ratio causes a sharp increase in $\bar{W}$. The decrease in the value of $\bar{W}$ in Figures $5(\mathrm{a}-\mathrm{c})$ displays the unfavorable impact of standard deviation on a bearing system's performance. Figures 6(a-b) establish an inverse relationship between variance and $\bar{W}$ suggesting that positive variance reduces $\bar{W}$ while negative variance increases it. Under the impact of skewness, $\bar{W}$ changes according to Figure 7. 
International Journal of Mathematical, Engineering and Management Sciences

Vol. 4, No. 4, 982-997, 2019

https://dx.doi.org/10.33889/IJMEMS.2019.4.4-078

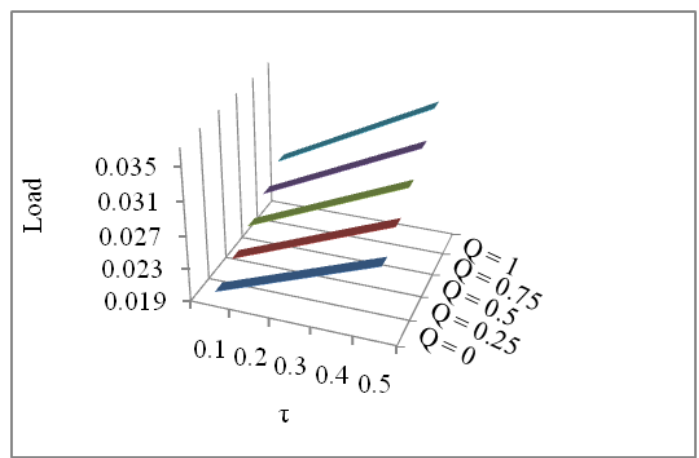

(a) $Q$

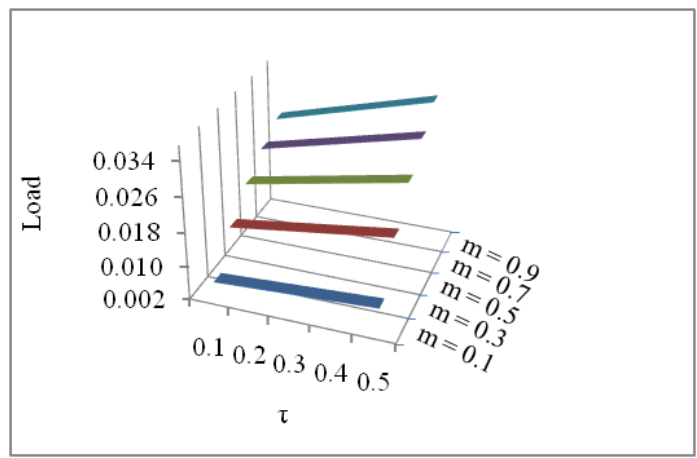

(b) $m$

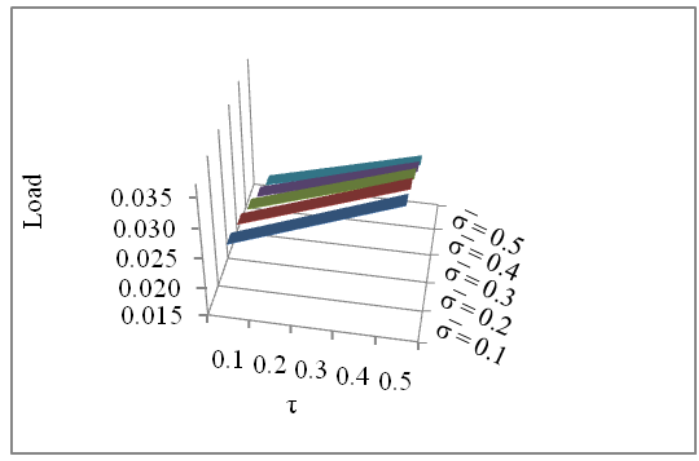

(c) $\bar{\sigma}$

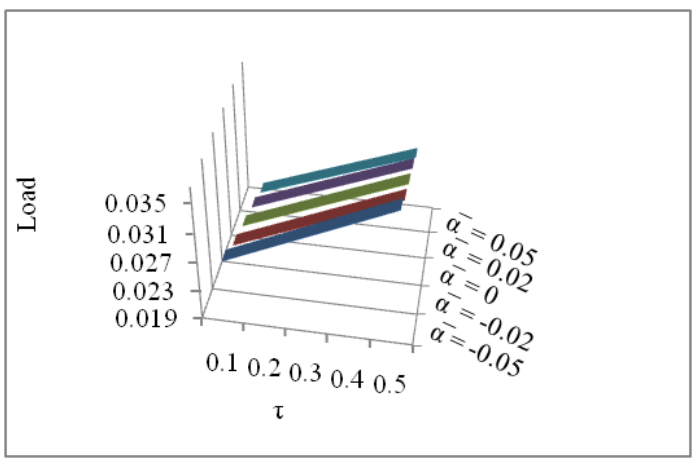

(d) $\bar{\alpha}$

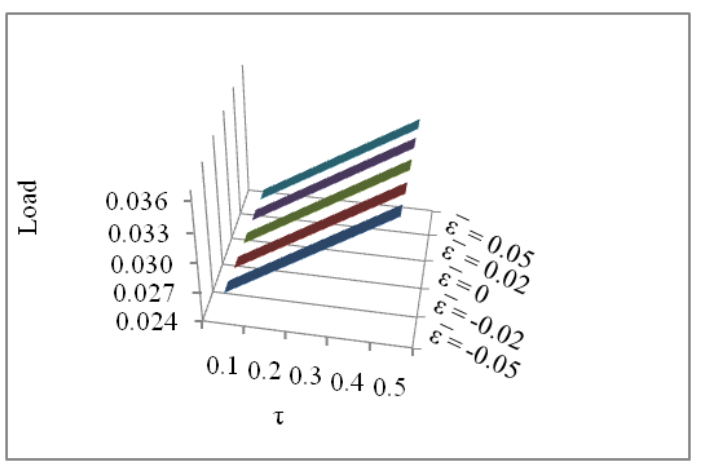

(e) $\bar{\varepsilon}$

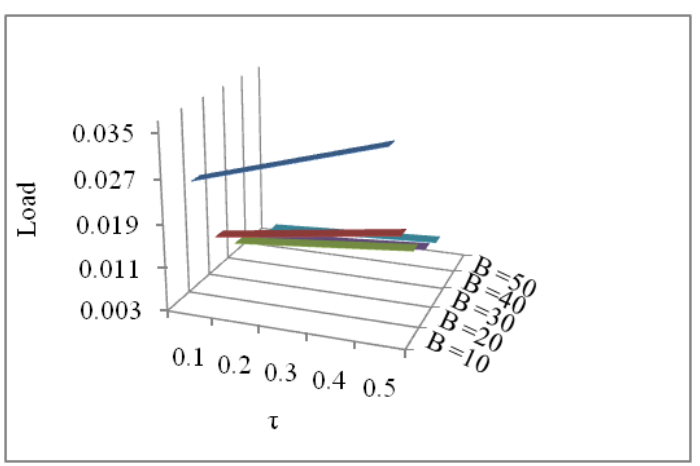

(f) $B$

Figure 2. Profile of load bearing capacity with regards to $\tau$ 
International Journal of Mathematical, Engineering and Management Sciences

Vol. 4, No. 4, 982-997, 2019

https://dx.doi.org/10.33889/IJMEMS.2019.4.4-078

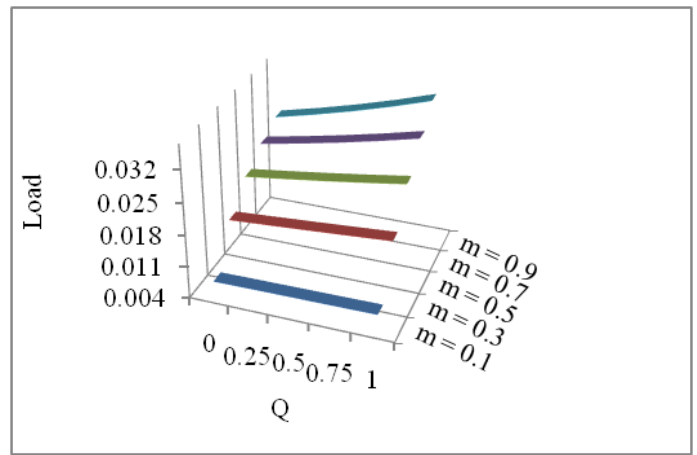

(a) $m$

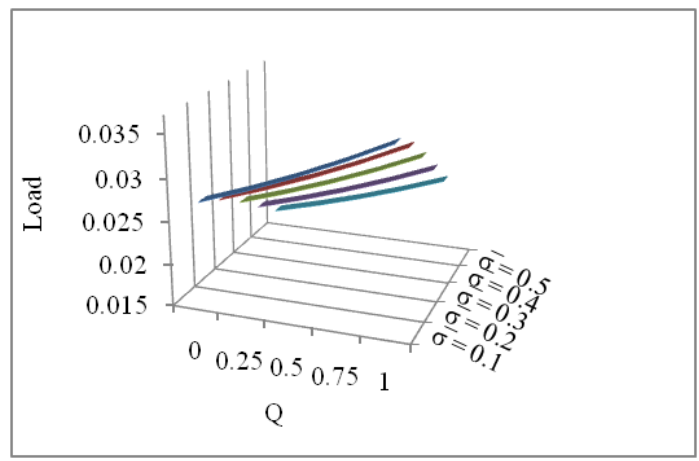

(b) $\bar{\sigma}$

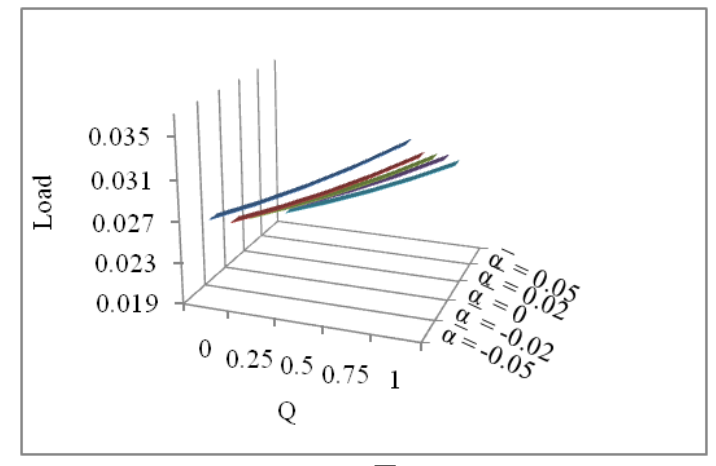

(c) $\bar{\alpha}$

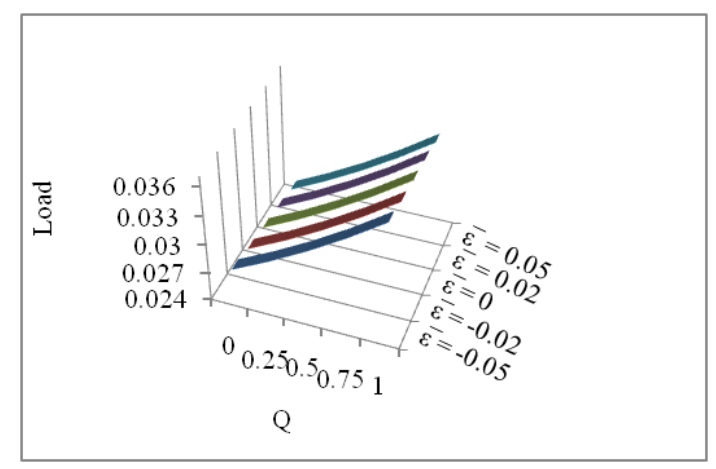

(d) $\bar{\varepsilon}$

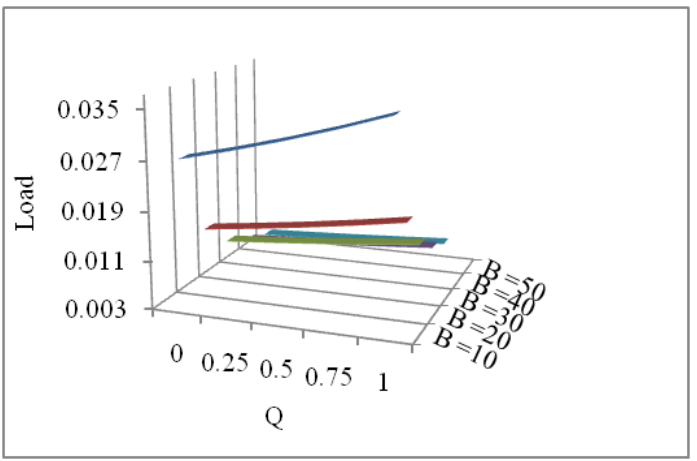

(e) $B$

Figure 3. Profile of load bearing capacity with regards to $Q$ 
International Journal of Mathematical, Engineering and Management Sciences

Vol. 4, No. 4, 982-997, 2019

https://dx.doi.org/10.33889/IJMEMS.2019.4.4-078

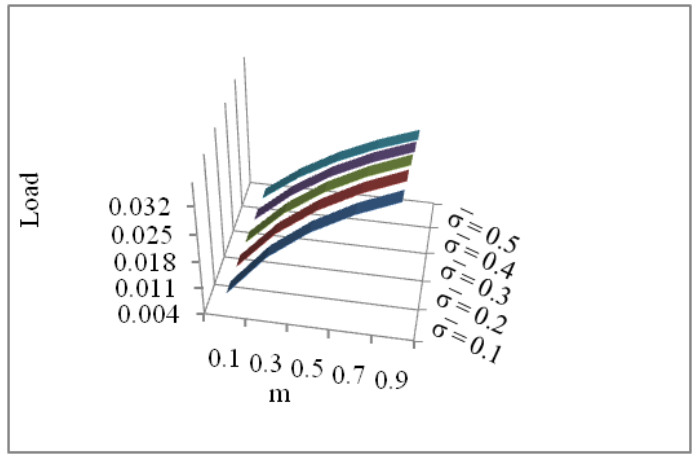

(a) $\bar{\sigma}$

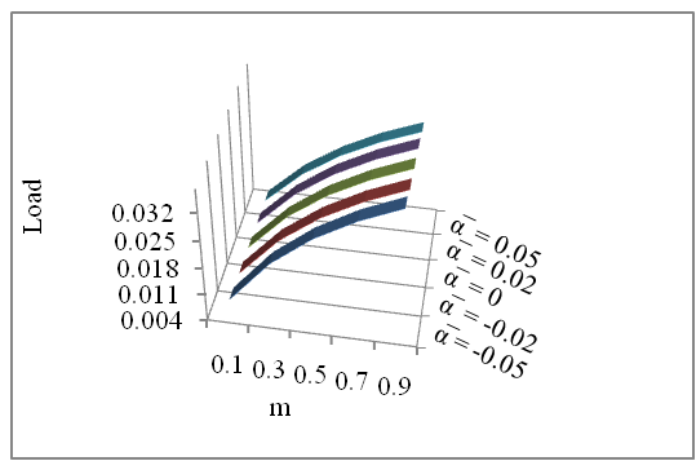

(b) $\bar{\alpha}$

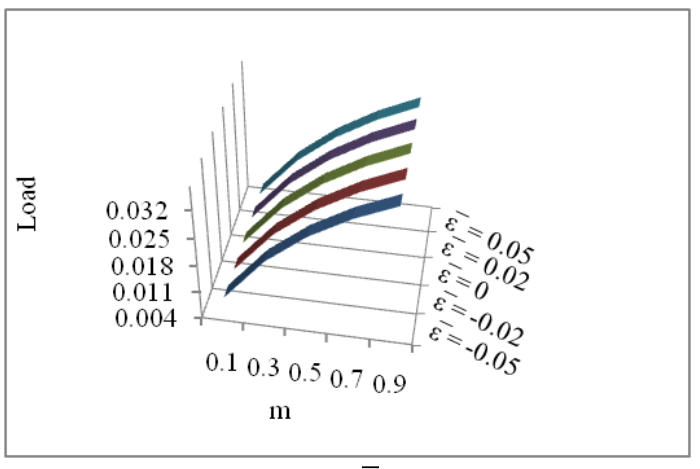

(c) $\bar{\varepsilon}$

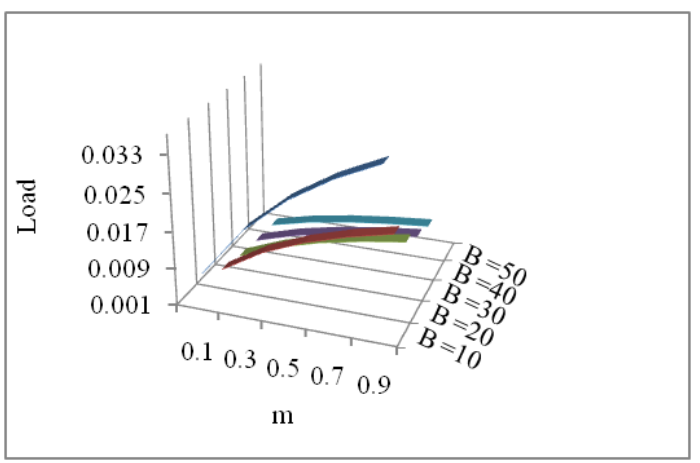

(d) $B$

Figure 4. Profile of load bearing capacity with regards to $m$ 
International Journal of Mathematical, Engineering and Management Sciences

Vol. 4, No. 4, 982-997, 2019

https://dx.doi.org/10.33889/IJMEMS.2019.4.4-078

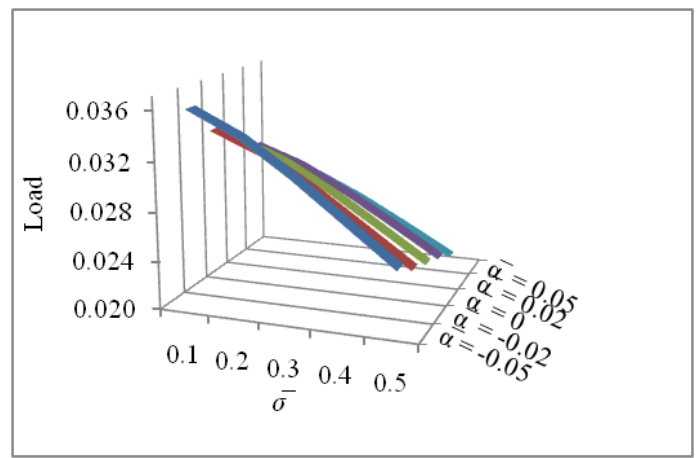

(a) $\bar{\alpha}$

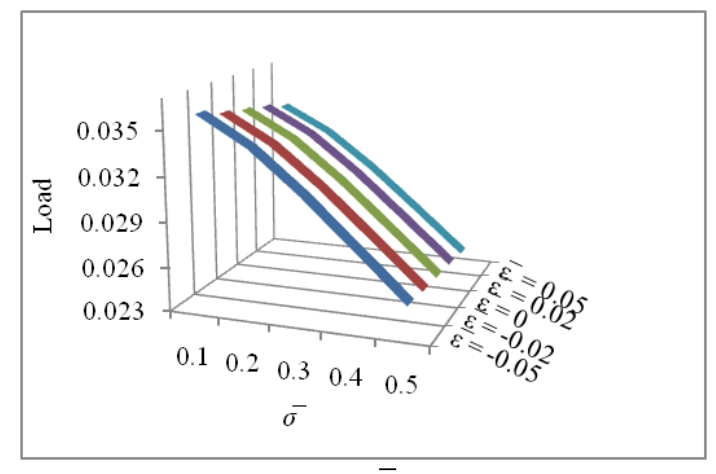

(b) $\bar{\varepsilon}$

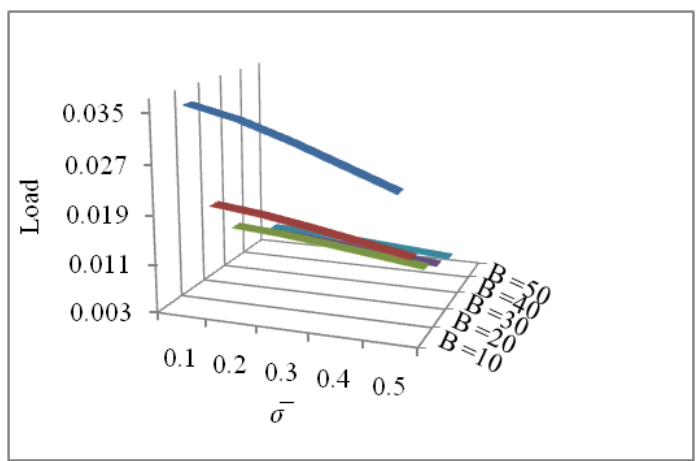

(c) $B$

Figure 5. Profile of load bearing capacity with regards to $\bar{\sigma}$

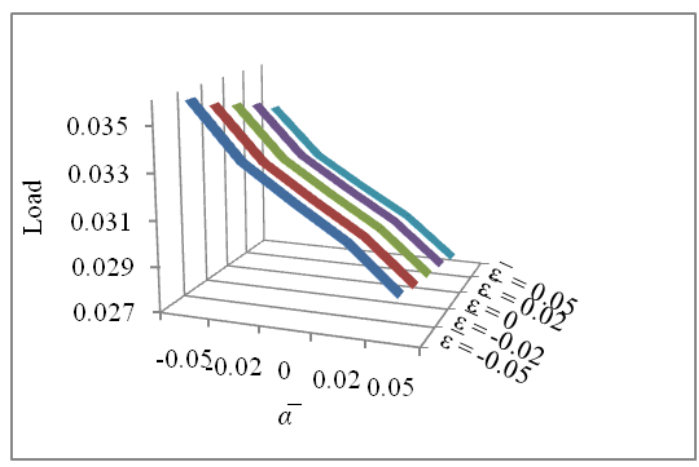

(a) $\bar{\varepsilon}$

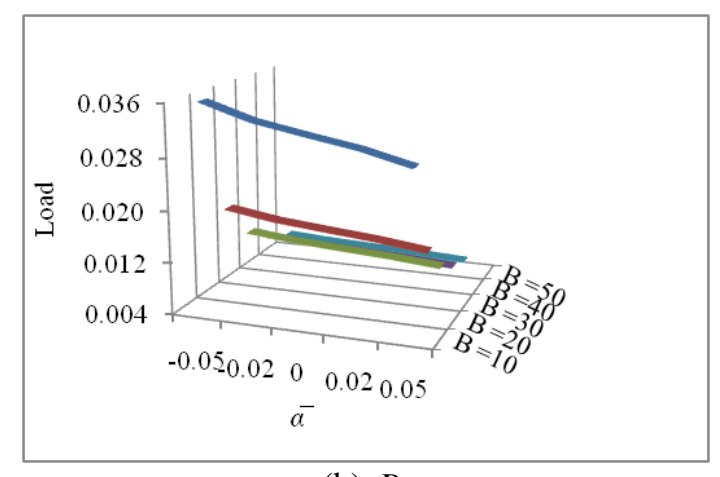

(b) $B$

Figure 6. Profile of load bearing capacity with regards to $\bar{\alpha}$ 
International Journal of Mathematical, Engineering and Management Sciences

Vol. 4, No. 4, 982-997, 2019

https://dx.doi.org/10.33889/IJMEMS.2019.4.4-078

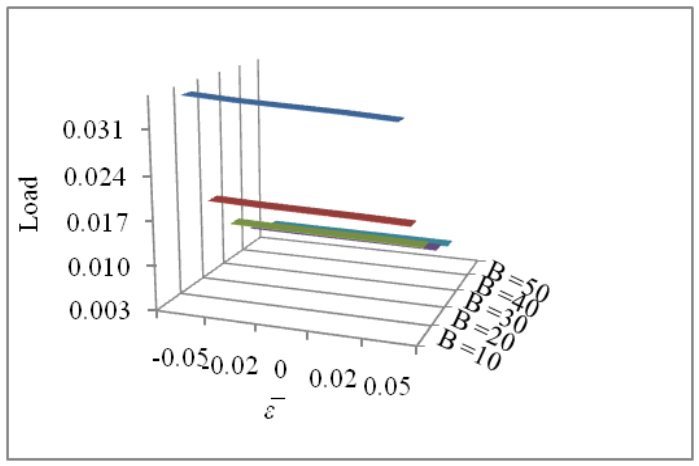

Figure 7. Profile of load bearing capacity with regards to $\bar{\varepsilon}$ and $B$

\section{Conclusion}

The Shliomis model of ferrofluid and the stochastic theory by Christensen have been used as the basis of this study to analyze the impact of changes in ferrofluid lubrication viscosity in the case of short bearings. The pressure distribution and the bearing system's capacity were analyzed numerically. The results obtained lead to the following conclusion:

- Thermal effect has a negative impact on a system's load bearing capacity.

- Magnetic strength in appropriate measures can be used to nullify the impact of the thermal effect.

- A left-ward skewed surface roughness increases the bearing capacity and a right-ward skewed surface roughness decreases the bearing capacity.

- This study is insightful since it ensures a higher freedom of magnitude than (Verma, 1986) and (Prajapati, 1994).

- The decrease in the bearing system's capacity due to roughness standard deviation can be nullified by $\tau$.

- When used magnetic fields, ferrofluid increase the capacity of short bearings in contrast to the systems functioning with conventional bearing.

This study provides new insights on improving bearing system's capacity. Additionally, the findings of this study support the theory stating that a bearing system's life can be starkly improved by controlling the loss of lubricants.

\section{Conflict of Interest}

The authors confirm that there is no conflict of interest to publish the paper in the journal.

\section{Acknowledgement}

The authors acknowledge with regards the constructive comments, fruitful suggestions and remarks of the reviewer/Editor, leading to an overhauling of the materials presented in the paper, necessitating the introduction of a few more references. 
International Journal of Mathematical, Engineering and Management Sciences

Vol. 4, No. 4, 982-997, 2019

https://dx.doi.org/10.33889/IJMEMS.2019.4.4-078

\section{References}

Basu, S.K., Sengupta, S.N., \& Ahuja, B.B. (2005). Fundamentals of tribology. Prentice-Hall of India private limited, New Delhi, India.

Bhat, M.V. (2003). Lubrication with a magnetic fluid. Team spirit Pvt. Ltd., India.

Christensen, H., \& Tonder, K. (1971). The hydrodynamic lubrication of rough bearing surfaces of finite width. Journal of Lubrication Technology, 93(3), 324-329.

Christensen, H., \& Tonder, K.C. (1969a). Tribology of rough surfaces: stochastic models of hydrodynamic lubrication. SINTEF Report 10/69.

Christensen, H., \& Tonder, K.C. (1969b). Tribology of rough surfaces: parametric study and comparison of lubrication model. SINTEF Report 22/69.

Deheri, G.M., \& Patel, J.R. (2011). Effect of surface roughness on the performance of a magnetic fluid based short bearing. Mathematics Today, 27, 10-23.

Deheri, G.M., Patel, J.R., \& Patel, N.D. (2016). Shliomis model based ferrofluid lubrication of a rough porous convex pad slider bearing. Tribology in Industry, 38(1), 46-65.

Freeman, P. (1962). Lubrication and friction. Chap.2, Pitman, London.

Gokul Raj, P., Esakki, B., \& Ganesan, S. (2019). Evaluation of mechanical strength characteristics of double ducted unmanned amphibious aerial vehicle using finite element analysis. International Journal of Mathematical, Engineering and Management Sciences, 4(2), 420-431.

Gupta A., Yadav, V., Sawant, V.A., \& Agarwal, R. (2019). Development of design charts considering the effect of backfill inclination and wall inclination on the seismic active pressure for $c-\phi$ soil. International Journal of Mathematical, Engineering and Management Sciences, 4(2), 409-419.

Hamrock, B.J. (1994). Fundamentals of fluid film lubrication. McGraw-Hill, New York.

Huang, W., \& Wang, X. (2016). Ferrofluids lubrication: a status report. Lubrication Science, 28, 3-26.

Khamari, B.K., Gunji, B., Karak, S.K., \& Biswal, B.B. (2019). Variation of microstructural and mechanical properties with respect to polarity in shielded metal arc welding of mild steel. International Journal of Mathematical, Engineering and Management Sciences, 4(2), 521-530.

Kumar, V.B., Suneetha, P.A., \& Prasad, K.R. (2013). Lubrication of journal bearing consider in thermal effect in two-layer fluid considering cavitation. International Journal of Advanced Engineering Technology, 4(4), 82-85.

Lin, J.R. (2016). Longitudinal surface roughness effects in magnetic fluid lubricated journal bearings. Journal of Marine Science and Technology, 24(4), 711-716.

Lin, J.R., Li, P.J., \& Hung, T.C. (2013a). Effects of non-newtonian ferrofluids on the performance characteristics of long journal bearings. Fluid Dynamics \& Materials Processing, 9(4), 419-434.

Lin, J.R., Li, P.J., \& Hung, T.C. (2013b). Lubrication performances of short journal bearings operating with non-Newtonian ferrofluids. Z. Naturforsch., 68, 249-254.

Majumdar, B.C. (2008). Introduction to tribology of bearings. S. Chand and Comp. Ltd., New Delhi, India.

Munshi, M.M., Patel, A.R., \& Deheri, G.M. (2017). Effect of slip velocity on a magnetic fluid based squeeze film in rotating transversely rough curved porous circular plates. Industrial Engineering Letters, 7(8), 28-42.

Naduvinamani, N.B., Apparao, S., Kadadi, A.K., \& Biradar, S.N. (2014). Combined effect of viscosity variation and surface roughness on the squeeze film lubrication of journal bearings with micropolar fluids. Tribology Online, 9(4), 175-183. 
International Journal of Mathematical, Engineering and Management Sciences

Vol. 4, No. 4, 982-997, 2019

https://dx.doi.org/10.33889/IJMEMS.2019.4.4-078

Patel, J.R., \& Deheri, G.M. (2013a). A comparison of porous structures on the performance of a magnetic fluid based rough short bearing. Tribology in Industry, 35(3), 177-189.

Patel, J.R., Deheri, G.M., \& Patel, P.A. (2018). Ferro-fluid lubrication of journal bearing with thermal effects. Mathematics Today, 34(A), 92-99.

Patel, N.S., Vakharia, D.P., Deheri, G.M., \& Patel, H.C. (2017). Experimental performance analysis of ferrofluid based hydrodynamic journal bearing with different combination of materials. Wear, 376377, Part B, 1877-1884.

Patel, R.M., Deheri, G.M., \& Vadher, P.A. (2010a). Performance of a magnetic fluid-based short bearing. Acta Polytechnica Hungarica, 7(3), 63-78.

Patel, R.M., Deheri, G.M., \& Vadher, P.A. (2010b). Magnetic fluid based short bearing and roughness effect. Journal of Science, 1(1), 102-107.

Patel, R.M., Deheri, G.M., \& Vadher, P.A. (2015). Hydromagnetic short bearings. Journal of Mechanical Engineering and Technology, 7(2), 19-32.

Patel, R.U., \& Deheri, G.M. (2013b). Effect of slip velocity on the performance of a short bearing lubricated with a magnetic fluid. Acta Polytechnica, 53(6), 890-894.

Prajapati, B.L. (1994). Magnetic fluid-based porous inclined slider bearing with velocity slip. Prajna, 7378.

Ramadevi, B., Ramana Reddy, J.V., \& Sugunamma, V. (2018). Influence of thermodiffusion on time dependent casson fluid flow past a wavy surface. International Journal of Mathematical, Engineering and Management Sciences, 3(4), 472-490.

Reddy, S.C.N., Reddy, G.J.C., \& Prasad, K.R.K. (2012). Effects of viscosity variation due to additives on squeeze film characteristics of long partial journal bearing: couple stress fluid model. International Journal of Mathematical Archive, 3(8), 2858-2868.

Shimpi, M.E., \& Deheri, G.M. (2010). Magnetic fluid based rough short bearing. Journal of the Balkan Tribological Association, 16(4), 484-497.

Shimpi, M.E., \& Deheri, G.M. (2012). Effect of deformation in magnetic fluid based transversely rough short bearing. Tribology-Materials Surfaces \& Interfaces, 6(1), 20-24.

Shliomis, M.I. (1974). Magnetic fluids. Soviet Physics Uspekhi, 17(2), 153-169.

Siddangouda, A., Biradar, T.V., \& Naduvinamani, N.B. (2013). Combined effects of surface roughness and viscosity variation due to additives on long journal bearing. Tribology-Materials, Surfaces \& Interfaces, 7(1), 21-35.

Singh, U.P., Medhavi, A., Gupta, R.S., \& Bhatt, S.S. (2018). Theoretical study of heat transfer on peristaltic transport of non-newtonian fluid flowing in a channel: Rabinowitsch fluid model. International Journal of Mathematical, Engineering and Management Sciences, 3(4), 450-471.

Sinha, P., Singh, C., \& Prasad, K.R. (1981). Effect of viscosity variation due to lubricant additives in journal bearings. Wear, 66(2), 175-188.

Tipei, N. (1962). Theory of lubrication: with applications to liquid-and gas-film lubrication. Stanford University Press.

Vashi, Y.D., Patel, R.M., \& Deheri, G.M. (2018). Ferrofluid based squeeze film lubrication between rough stepped plates with couple stress effect. Journal of Applied Fluid Mechanics, 11(3), 597-612.

Verma, P.D.S. (1986). Magnetic fluid-based squeeze films. International Journal of Engineering Sciences, 24(3), 395-401. 
International Journal of Mathematical, Engineering and Management Sciences

Vol. 4, No. 4, 982-997, 2019

https://dx.doi.org/10.33889/IJMEMS.2019.4.4-078

\section{Nomenclature}

$B \quad$ breadth of the bearing

$\boldsymbol{h} \quad$ film thickness ( $\mathrm{mm})$

$h \quad$ mean film thickness $(\mathrm{mm})$

$h_{s} \quad$ deviation from mean level

$h_{1} \quad$ maximum film thickness

$h_{2} \quad$ minimum film thickness

$\bar{h} \quad$ non dimensional film thickness

$H \quad$ magnitude of $\bar{H}$

$H_{0} \quad$ constant magnetic field

I sum of moments of inertia of the particle per unit volume

$k_{B} \quad$ Boltzmann constant

$L \quad$ length of the bearing ( $B<<L$ )

$m \quad$ aspect ratio

$\bar{M} \quad$ magnetization vector

$M_{0} \quad$ equilibrium magnetization

$n \quad$ number of particles per unit

$p \quad$ pressure in the film region

$\bar{p} \quad$ non-dimensional film pressure

$\bar{q} \quad$ fluid velocity

$\bar{S} \quad$ internal angular momentum vector

$T \quad$ temperature (K)

$u, v, w \quad$ the velocities components in $x, y$

and $z$ directions the velocities components of upper

surfaces in $x, y$ and $z$ directions

the velocities components of lower

$u_{b}, v_{b}, w_{b} \quad$ surfaces in $x, y$ and $z$ directions

$V \quad$ volume of the particle

$W \quad$ load capacity (N)

$\bar{W} \quad$ non-dimensional load capacity

$x, z \quad$ the bearing width and length

coordinates

$y \quad$ fluid film thickness coordinate

$\alpha \quad$ variance (mm)

$\bar{\alpha} \quad$ non- dimensional variance

$\varepsilon \quad$ skewness $\left(\mathrm{mm}^{3}\right)$

$\bar{\varepsilon} \quad$ skewness in dimensionless form

$\eta_{0} \quad$ viscosity of the main liquid

$\mu \quad$ magnetic moment of a particle

$\mu_{0} \quad$ permeability of the free space

$\rho \quad$ lubricant density

$\sigma \quad$ standard deviation (mm)

$\bar{\sigma} \quad$ dimensionless standard deviation

volume concentration of the

$\phi \quad$ particles $(=n V)$

$\tau \quad$ magnetization parameter

$\bar{\Omega} \quad$ fluid vorticity 